\title{
MICROLEAKAGE OF DIFFERENT RESIN COMPOSITES OF CLASS II POSTERIOR RESTORATIONS PLACED AT THE CEMENTO-ENAMEL JUNCTION
}

\author{
Hadeel A. Sabry* and Ebaa I Al-Agha**
}

\begin{abstract}
Aim of the study: This study was directed to evaluate the microleakage of different types of composite resin in class II posterior restoration at the cement-enamel junction CEJ.

Materials and methods: Eighty one freshly extracted molars were selected. The teeth were divided into three main groups (27 each) according to the material used. Group 1: samples were restored with packable resin composite. Group 2: samples were restored with packable resin composite lined with 1-1.5mm layer of flowable resin composite. Group 3: samples were restored with hybrid resin composite. Each group was divided into three subgroups ( 9 each) according to the storage time. Subgroup A, B and C: storage time was 24 hours, 1 month and 3 months respectively. The gingival margin was located at the CEJ. The teeth were restored and microleakage testing was performed using dye penetration method. The data were collected and statistically analyzed.
\end{abstract}

Results: The packable composite group recorded the highest microleakage values followed by hybrid composite group then flowable-lined packable composite group and this was statistically with high significance $(\mathrm{p}<0.001)$. The three groups showed the least microleakage values after one month followed by three months storage while the highest values were after 24 hours storage.

Conclusion: None of the tested materials was able to completely eliminate marginal microleakage at CEJ but the use of flowable resin composite as a liner under packable resin composite showed a reduction in microleakage compared to the other types.

KEYWORD: CEJ, class II restoration, packable composite, flowable composite, hybrid composite, microleakage, storage time.

\section{INTRODUCTION}

An ideal restorative material would create a permanent and perfect seal between the restoration margin and the tooth structure. Imperfect bonding leaves a microscopic gap that allows the infiltration of bacteria, fluids, molecules and ions between the restoration and the tooth structure, commonly referred to as microleakage. ${ }^{(1)}$ Microgap formation may result from shrinkage of the composite during polymerization or from mismatches between either

* Lecturer of Biomaterials, Faculty of Dentistry, October 6 University

** Assistant Lecturer, Operative Dentistry, Faculty of Dentistry, October 6 University 
the coefficients of thermal expansion of the tooth and the composite or between the elastic modulus of the tooth and the composite. Although some degree of microleakage will occur with most dental materials, slight leakage can be tolerated by the pulp and irritants are often removed by pulpal blood flow. However in some circumstances, microleakage becomes a source of postoperative sensitivity, recurrent caries and subsequently an eventual failure of the restoration. ${ }^{(2)}$ Significant advances provided by adhesive systems and improvement in the physical and mechanical properties of resin composites, along with the increasing esthetic demand by the patients, have made esthetic direct restorations on the posterior segment a common procedure in the dental practice. However, there are advantages and disadvantages to using resin composites on posterior teeth. The advantages are conservative preparation, esthetics and adhesion to the dental structure. The disadvantages are technique sensitivity, polymerization shrinkage, postoperative sensitivity and marginal microleakage. (3) One of the recent composite resin materials is the packable resin composite which provide improved handling properties by changing the filler phase or matrix system, the viscosity of these materials was increased to resist a greater condensing force. ${ }^{(4)}$ Also, flowable resin composite have been suggested as a liner beneath composites, assuming that the low viscosity material will better fill irregular internal surfaces and proximal boxes, thereby improving final marginal integrity. ${ }^{(5)}$ The literature has shown that major marginal microleakage occurs on the gingival surfaces located in dentin or cementum. This is because these two structures do not show the same conditions for adhesion to resin composites, of which enamel has better results. In addition, difficulty in accessing the proximal boxes of the preparations and the control of contamination are complicating factors for restorative technique. In addition, dentin bonding is more difficult because the heterogeneous nature of the tissue requires the bonding system to accommodate simultaneously the properties of the hydroxyapatite, collagen, smear layer, dentinal tubules and fluids. ${ }^{(6)}$

\section{MATERIALS AND METHODS}

A total number of eighty one freshly extracted human molars were selected for this study. The selected teeth were cleaned from both tissue and calculus deposits then scrubbed with hard tooth brush under running water and finally dried with oil-free compressed air. Any defected tooth was discarded and replaced by another one. Class II cavity was prepared in one proximal surface for each molar following the general principles of cavity preparation. The cavities were prepared by using carbide round bur revolving at a high speed with water air spray in the central fossa of each tooth, the bur was changed to carbide tapered fissure bur revolving at a high speed then a carbide inverted cone bur was used to finish the floor of the cavity. The cavities were approximately $4 \mathrm{~mm}$ in width and $4 \mathrm{~mm}$ in depth and the gingival margin was about $1.5 \mathrm{~mm}$ from the axial wall. The depth of the gingival floor was placed at CEJ. The cavo-surface margins for all walls were prepared without bevels. The teeth were randomly divided into three main groups (27 each) according to the material used. Group 1: samples were restored with packable resin composite (Tetric Ceram HB, Ivoclar-Vivadent). Group 2: samples were restored with packable resin composite lined with a $1-1.5 \mathrm{~mm}$ layer of flowable resin composite (Tetric Flow, Ivoclar-Vivadent). Group 3: samples were restored with hybrid resin composite (Prime Dent, Prime Dent.USA). Each group was divided into three subgroups (9 each) according to the storage time. Subgroup A: storage time was 24 hours. Subgroup B: storage time was 1 month. Subgroup C: storage time was 3 months. The cavity walls for each tooth were etched with $37 \%$ phosphoric acid gel (Total Etch, IvoclarVivadent) for 20 seconds, rinsed thoroughly for 30 seconds with water according to the manufacturer's 
instructions then dried for 5 seconds with oil free air syringe. Bonding agent (Prime Dent Adhesive bonding system.USA) was applied to the cavities by a brush and spreading was done by a gentle blow of oil free air then light cured for 20 seconds according to the manufacturer's instructions using a visible light curing unit (3H, Fit-Light S.China). In group A, after placing celluloid matrix band (GoMat, IvoclarViva Dent), packable resin composite was placed in increments by a plastic instrument then each increment was light cured for 20 seconds according to the manufacturer's instructions. In Group B, $1-1.5 \mathrm{~mm}$ thick layer of flowable resin composite was placed without a celluloid matrix band in order to easily manipulate and standardize the thickness of the increment then light cured for 20 seconds according to the manufacturer's instructions then packable resin composite was placed in increments over the flowable liner to fill the prepared cavity with the aid of the celluloid band. In Group C, after placing celluloid matrix band, hybrid resin composite was placed in increments by a plastic instrument then light cured for 20 seconds according to the manufacturer's instructions. After restoration, samples were finished by finishing bur and rubber flame in a low speed hand piece. Specimens were stored in distilled water at $37^{\circ} \mathrm{C}$ and humidity $100 \%$ in an incubator for one day, one month and three months according to each storage interval until microleakage testing. All teeth surfaces except the restoration and $1 \mathrm{~mm}$ away from the cavity margins were coated with nail varnish then by sticky wax to insure complete sealing of the samples. After sealing, samples were immersed in $2.5 \%$ methylene blue dye at $37^{\circ} \mathrm{C}$ for 24 hours, removed from the dye, cleaned under tap water then left to dry for another 24 hours. Samples were sectioned mesio-distally by using a double-sided diamond disk rotating at a low speed then the crown of each tooth was splitted longitudinally in two halves by a bi-beveled chisel. Each sample was examined microscopically by a stereomicroscope using a computerized image analyzing system. A digital image of the restoration was captured by a digital camera mounted on a stereomicroscope (Olympus SZ-PT-Japan) at a 25X magnification. Image analysis software was used to measure the linear dye penetration in microns at four different points (cervical, mesio-occlusal, disto-occlusal and at the center of the occlusal surface). Microleakage was measured in microns and the results were statistically analyzed.

\section{RESULTS}

\section{Packable resin composite}

Dye penetration mean \pm standard deviation values $(\mu \mathrm{m})$ at CEJ after 24 hrs, 1 month and 3 months were $2156 \pm 325,1305 \pm 390$ and $1451 \pm 290$ respectively. It was observed that $24 \mathrm{Hrs}$ showed a higher leakage rate as recorded by dye penetration; 3 months recorded an intermediate leakage rate while 1 month recorded a lower leakage rate and this was statistically significant $(\mathrm{p}<0.05)$.

\section{Packable resin composite + Flowable liner}

Dye penetration mean \pm standard deviation values $(\mu \mathrm{m})$ at CEJ after $24 \mathrm{hrs}, 1$ month and 3 months were $1717 \pm 367.3,1127 \pm 335.6$ and $1307 \pm 329$ respectively. It was observed that $24 \mathrm{Hrs}$ showed a higher leakage rate as recorded by dye penetration; 3 months recorded an intermediate leakage rate while 1 month recorded a lower leakage rate and this was statistically non-significant ( $p>0.05)$.

\section{Hybrid resin composite}

Dye penetration mean \pm standard deviation values $(\mu \mathrm{m})$ at CEJ after $24 \mathrm{hrs}, 1$ month and 3 months were $2032 \pm 368.3,1297 \pm 389.1$ and 1691 \pm 473.48 respectively. It was observed that $24 \mathrm{Hrs}$ showed a higher leakage rate as recorded by dye penetration; 3 months recorded an intermediate leakage rate while 1 month recorded a lower leakage rate and this was statistically non-significant $(\mathrm{p}>0.05)$. 
TABLE (1) Dye penetration results $(\mu \mathrm{m})$ recorded for all tested groups at CEJ.

\begin{tabular}{|l|c|c|c|c|c|c|}
\hline \multirow{2}{*}{ Storage time } & \multicolumn{2}{|c|}{24 Hours } & \multicolumn{2}{c|}{1 Month } & \multicolumn{2}{c|}{3 Months } \\
\cline { 2 - 7 } Composite type & Mean & SD & Mean & SD & Mean & SD \\
\hline Packable & 2156 & 325 & 1305 & 390 & 1451 & 290 \\
\hline Flowable-lined packable & 1717 & 367.3 & 1127 & 335.6 & 1307 & 329 \\
\hline Hybrid & 2032 & 368.3 & 1297 & 389.1 & 1691 & 473.48 \\
\hline
\end{tabular}

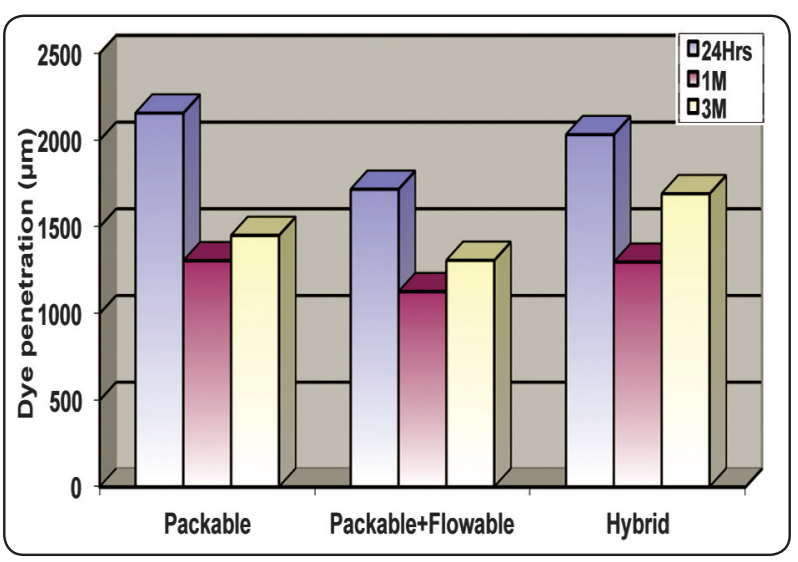

Fig. (1) A bar chart of dye penetration mean values $(\mu \mathrm{m})$ for all groups at CEJ.

\section{DISCUSSION}

Microleakage is one of the major disadvantages of resin composite restorations. It results from failure of the material to adapt to dental structure, usually at the gingival margin. When a layer of resin composite is packed in the cavity and cured, a competition between shrinkage of the composite and adhesion to the substrate begins. Stresses produced by polymerization shrinkage are critical to adhesion between the resin composite and the tooth structure. If shrinkage stresses are stronger than the bond strength between the resin and adhesive system, the tooth-restoration interface can break, forming a gap that will allow marginal microleakage.
This shrinkage depends on many factors, such as cavity size and shape, substrate type and location of the margins, restorative material and the technique of placement and polymerization. ${ }^{(7)}$ In this study, statistically significant difference was observed in all dentin margins. Bonding to dentin, presents a much greater challenge. Dentin is an intrinsically hydrated tissue, penetrated by a maze of 1 to $2.5 \mu \mathrm{m}$ diameter fluid filled dentin tubules. Movement of fluid from the pulp to the dentin-enamel junction is a result of a slight but constant pulpal pressure. ${ }^{(8)}$ Pulpal pressure has a magnitude of 25 to $30 \mathrm{~mm} \mathrm{Hg}$ or 34 to $40 \mathrm{~cm} \mathrm{H}_{2} \mathrm{O} .{ }^{(9)}$ Dentinal tubules enclose cellular extensions from the odontoblasts and therefore are in direct communication with the pulp. Inside the tubules lumen, other fibrous organic structures (the lamina limitans) can be observed; these substantially decrease the functional radius of the tubule. The relative area occupied by dentin tubules decrease with increasing distance from the pulp. The number of tubules decrease from about 45,000 per $\mathrm{mm} 2$ close to the pulp to about 20,000 per mm2 near the dentin-enamel junction. ${ }^{(10)}$ The tubules occupy an area of only $1 \%$ of the total surface near the dentin-enamel junction, whereas they comprise $22 \%$ of the surface close to the pulp. (11) The average tubule diameter ranges from 0.63 $\mathrm{mm}$ at the periphery to $2.37 \mathrm{~mm}$ near the pulp. ${ }^{(12)}$ Adhesion can be affected by the remaining dentin thickness after tooth preparation. Bond strengths are 
generally less in deep dentin than in superficial dentin. ${ }^{(13)}$ Whenever tooth structure is prepared with a bur or other instrument, residual organic and inorganic components form a smear layer of debris on the surface. ${ }^{(14)}$ The smear layer fills the orifices of dentin tubules forming smear plugs and decrease dentin permeability by up to $86 \% .^{(15)}$ The composition of the smear layer is basically hydroxyapatite and altered de-natured collagen. This altered collagen may even acquire a gelatinized consistency as a result of the friction and heat created by the preparation procedure. ${ }^{(16)}$ Submicron porosity of the smear layer still allows for diffusion of dentinal fluid. ${ }^{(17)}$ The removal of the smear layer and smear plugs with acidic solutions may result in an increase of the fluid flow on to the exposed dentin surface. This fluid may interfere with adhesion because hydrophobic resins do not adhere to hydrophilic substrates even if resin tags are formed in the dentin tubules. ${ }^{(18)}$ Several additional factors affect dentin permeability. Besides the use of vasoconstrictor in local anesthesia which decrees pulpal pressure and fluid flow in the tubules, other factors such as the radius and length of the tubules, the viscosity of dentin fluid, the pressure gradient, the molecular size of the substances dissolved in the tubular fluid, and the rate of removal of substances by the blood vessels in the pulp affect permeability. (19) All of these variables make dentine a dynamic substrate and consequently a very difficult substrate for bonding. ${ }^{(20)}$ Least dye penetration values were recorded when packable resin composite was used in combination with flowable resin liner. The improved flow of the flowable resin composite resulted from reducing the filler content is likely to facilitate adaptation as the low viscosity materials offer better wettability to the underlying substrate. Also, the low viscosity composite liner may act as a stress absorbing layer due to its lower elastic modulus (from 1 to $5 \mathrm{GPa}$ ), and avoid disruption of the bond promoted by the adhesive resin during polymerization shrinkage or in the case it is disrupted, there is a great chance that dentinal tubules will be kept sealed. The lower elastic modulus of a material indicates a greater ability to flex with the tooth to accommodate the inherent modulus of the tooth, which will eliminate gap formation and subsequent microleakage. This was in agreement with Estafan Am and Prager. (21) However, flowable composite has some disadvantages. The volumetric curing shrinkage of flowable composite is considerably higher and most of the physical properties are less than from hybrid composites. ${ }^{(22)}$ It should be noted that voids can be introduced during liner placement and leakage can directly result from poorly adapted flowable material, the practitioner must carefully apply the material at the cervical margin in one direction using a gentle releasing motion. This will help to reduce the amount of trapped air when the material is exposed and help to eliminate voids from mishandling during syringe application. ${ }^{(23)}$ The results showed no significant difference between samples restored with packable resin composite alone and samples restored with hybrid resin composite but improved handling characteristics developed for the packable composite have made them more suitable for posterior application compared to traditional composites. The increase in the amount of filler in the packable composite, leads to decrease in polymerization shrinkage because only the resin matrix shrinks not the filler particles. Therefore, a higher amount of filler lowers the coefficient of thermal expansion and leads to minimal marginal stress and microleakage. ${ }^{(24)}$ Due to modification of the filler particle of the packable resin composites, they are more viscous and less sticky than the traditional resin composites, which allow them to better simulate the behavior of amalgam during condensation. This was in agreement with AL Neme \& BB Maxson. (25) However, for the gingival proximal area of posterior teeth where isolation is difficult and access and visibility are compromised, it has been suggested 
that flowable composite materials be used as a liner under the packable resin composite for the proximal box area. The rationale for using flowable composites in this way is to improve marginal adaptation while decreasing internal voids resulting in a reduction in marginal leakage. (26) Denise Estafan (27) used packable resin composite alone and the samples showed at least one void. These voids may be due to various properties including polymerization shrinkage, high viscosity, high modulus of elasticity, poor wettability or depth of cure. Also, recommendations from manufacturers for many of the packable resin composite claim a depth of cure of 5-6 $\mathrm{mm}$ as opposed to a maximum of $2 \mathrm{~mm}$ which is recommended for most other light cure resin restorative materials and this may help in void formation. Voids in restorations may cause the restoration to fail and lead to caries and possible pulp involvement. This result was in agreement with the present study. In this study least dye penetration was found at 1 month storage time then at 3 months then at 1 day. This may be explained by the water sorption potential of composite resins. Storage of the specimens for 1 month would allow some water sorption by the resin and subsequent hygroscopic expansion of the restoration. This expansion would not establish a perfect marginal seal but could contribute to less dye penetration. Conversely, 24 hours would not permit the time necessary for this phenomenon to occur. ${ }^{(28)}$ This was in agreement with YAP and Wang HB ${ }^{(29)}$, they found a significant decrease in marginal gaps between 1 day and 1 week and they found that all materials showed a decrease in gap width within 1 week storage in water. This result appear to support the results obtained with Momal and McCabe. ${ }^{(30)}$ who concluded that expansion caused by water sorption is able to rapidly compensate the effects of polymerization shrinkage. On the other hand, Davidson and Feilzer ${ }^{(31)}$ are of the opinion that the water sorption is a slow process and its compensatory effects for polymerization shrinkage often come too late. It is important to note that the amount or rate of water sorption and compensation is a product specific and may be dependent on the chemistry of the resin matrix. ${ }^{(32)} \mathrm{Li} \mathrm{HP}$ and Burrow $\mathrm{ME}^{(33)}$ found that a minimum of 1 year of storage in water is necessary to correctly evaluate its effect on microleakage. A significant improvement of the marginal sealing was observed by Carlos Torres and Maria de Araujo ${ }^{(34)}$ at 6 months in comparison to base line. This may be attributed to the water sorption by composite resin which expand hygroscopically and contribute to closing marginal gaps. Youngson CC and Jones JC ${ }^{(35)}$ noticed that marginal microleakage decreased after the second or fourth week in water storage. These results were in agreement with the present study. Composites shrink as they polymerize, creating stresses of up to $7 \mathrm{MPa}$ within the composite mass depending on the configuration of the preparation. ${ }^{(36)}$ When the composite is bonded to one surface only such as in the case of a direct facial veneer, stresses within the composite are relieved by flow from the un-bonded surface. However, stress relief within a threedimensional bonded restoration is limited by its configuration factor or C-factor. ${ }^{(37)}$ In this study, stress relief was limited because flow can occur only from two surfaces. Unrelieved stresses in the composites may cause internal bond disruption as well as marginal gaps around the restorations that increase microleakage. ${ }^{(38)}$

\section{CONCLUSION}

None of the tested materials was able to completely eliminate marginal microleakage at CEJ

The use of flowable resin composite as a liner under packable resin composite showed a reduction in microleakage in comparison with the use of packable resin composite solely or the use of hybrid composite.

Microleakage is affected significantly by storage time with packable composites, while it's non significant with flowable and hybrid composites. 


\section{REFERENCES}

1. Kidd EA. Microleakage, a review. Journal of Dentistry 4(5):199-206 (1976).

2. Barkmeier WW, Cooley RL Laboratory evaluation of adhesive systems. Oper Dent, suppl 5:50-61 (1992).

3. Baratieri LN, Monteiro S, Jr. Andrada MAC, Viera LCC. Foundations and possibilities. Livraria ,Santos, Sao Paulo. Journal of restorative dentistry (2001).

4. Cobb DS, Mac Gregor KM, Vargas MA. The physical properties of packable and conventional posterior resin based composites. J Am Dent Assoc 131: 1610-1615 (2000).

5. Neme AM, Maxon BB, PinkFE, Aksu MN. Microleakage of class II packable resin composite restorations. Oper Dent 27: 600-605 (2002).

6. Anusavice KJ. Philips science of dental materials. $10^{\text {th }}$ ed. Philadelphia VVB. Saunders Company (1996).

7. Davidson CL, De Gee AJ \& Feilzer A. The competition between the composite-dentin bond strength and the polymerization contraction stress. Journal of Dental Research 63(12) 1396-1399 (1984).

8. Brannstrom M, Linden LA, Johnson G. Movement of dentinal and pulpal fluid caused by clinical procedures. J Dent Res 47: 679-682 (1968).

9. Terka LG, Van Hassel HJ. Testing sealing properties of restorative materials against moist dentin. J Dent Rest 66: 1758-1764 (1987).

10. Garberoglio R, Brannstrom M, Scanning electrom microscope investigation of human dentinal tubules, Arch Oral Biol 21: 355-362 (1976).

11. Pashley DH, Dentin: a dynamic substrate- a review, scanning microscope 3:161-176 (1989).

12. Marchetti C, Piacenttini C, Menghini P, Morphometric computerized analysis on the dentinal tubules and the collagen fibers in the dentin of human permanent teeth, Bull Group Int Rech Sci Stomatol Odontol 35: 125-129 (1992).

13. Mitchem JC, Gronas DG. Effects of time after extraction and depth of dentin on resin dentin adhesives. JADA 113: 285-287 (1986).

14. Ishioka S, Caputo AA. Interaction between the dentinal smear layer and composite bond strengths. J Prosthet Dent 61: 180-185 (1989).
15. Pashley DH, Livingstone MJ, Greenhill JD. Regional resistances to fluid flow in human dentin in vitro. Arch Oral Biol 23: 807-810 (1978).

16. Eick JD. The dentinal surface: its influence on dentinal adhesion. Quintessence Int 22: 967-977 (1991).

17. Pashley DH. The effects of acid etching on pulpodentinal complex. Oper Dent 17: 229-242 (1992).

18. Torney D. The restorative ability of acid-etched dentin. J Prosthet Dent 39: 169-172 (1978).

19. Reeder OW. Dentin permeabity determinants by hydraulic conductance. J Dent Res 57: 187-193 (1978).

20. Soderholm K, JM. Correlation of in vivo and in vitro performance of adhesive restorative materials, a report of the ASC MD156 Task Group on test methods for the adhesion of restorative materials. Dent Mater 7: 74-83 (1991).

21. Estafan AM, Estafan D, Prager MC. Microleakage study of flowable composite resin systems. Compendium 21(9): 705-714 (2000).

22. Bayne SC, Thompson JY, Swift EC, Jr. Stamatiades P \& Wilkerson MA. A characterization of first generation flowable composites. Journal of the American Dental Association 129(5): 567-576 (1998).

23. Chuang SF, Liu JK, Chao CC, Liao FP \& Chen YHM. Effects of flowable composite lining and operator experience on microleakage and internal voids in Class II composite restorations. J Prosth Dent 85(2): 177-183 (2001).

24. Denise Estafan, Ashraf Estafan \& Karl F. Cavity wall adaptation of resin based composites lined with flowable composite. Am J Dent 13(4) 192-194 (2000).

25. AL Neme, BB Maxson, FE Pink, MN Aksu. Microleakage of Class II packable rein composites lined with flowables. J Oper Dent 27: 600-605 (2002).

26. Chuang SF, Liu JK, Chao CC, Liao FP \& Chen YHM. Effects of flowable composite lining and operator experience on microleakage and internal voids in Class II composite restorations. J Prosth Dent 85(2): 177-183 (2001).

27. Denise Estafan, Ashraf Estafan \& Karl F. Cavity wall adaptation of resin based composites lined with flowable composite. Am J Dent 13(4) 192-194 (2000).

28. A. U. J. YAP, K. C. SHAH \& C. L. CHEW. Marginal gap formation of composites in dentine: effect of water storage. Journal of oral rehabilitation 30; 236-242 (2003). 
29. YAP, AUJ, Wang HB, Siow KS \& Gan LM. Polymerization shrinkage of visible light cured composites. J Oper Dent 2598 (2000).

30. Momal Y \& Mc Cabe JF. Hygroscopic expansion of resin based composites during 6 months of water storage. British Dental Journal 591 (1994).

31. Davidson CL, Feilzer AJ. Polymerization shrinkage and polymerization shrinkage stress in polymer based restoratives. Journal of Dentistry 6, 435 (1997).

32. AUJ, Yap KC Shahand $\mathrm{Cl}$ Chew. Marginal gap formation of composites in dentin, effect of water storage. Journal of Oral Rehabilitation. 30, 236-242 (2003).

33. Li HP, Burrow ME, Tyas MJ. The effect of long term storage on nanoleakage. J Oper Dent 26: 609-616 (2001).
34. Carlos Torres, Maria de Araujo, Adriana de Mella Torres. Effect of dentin collagen removal on microleakage and bonded restorations. J Aesth Dent 6: 33-42 (2004).

35. Youngson CC, Jones JCG, Fox K, Smith IS, Gale M. A fluid filtration and clearing technique to asses microleakage associated with three time bonding systems. J Dent 27: 223-233 (1999).

36. Hegdahl T, Gjerdet NR. Contraction stresses of composite filling materials. Acta Odontol Scand 35: 191-195 (1977).

37. Feilzer A, De Gee AJ, Davidson CL. Setting stress in composite resin in relation to configuration of the restoration. $\mathrm{J}$ Dent Res 66: 1636-1639 (1987).

38. Perdigao J. The interaction of adhesive systems with dentin. Am J Dent 9: 167-173 (1996). 